\title{
Simulation and effects analysis of region models for interior fire hazard
} Simulación y análisis de efectos del modelo de región para los riesgos de incendio interior

Tao Luo (Main and Contact Autor)

Opening project of key laboratory of deep mine construction, Henan Polytechnic University, China

lqt1@qq.com

2001 Century Avenue, Jiaozuo, Henan Province, Jiaozuo 454000, China +8613514187401

\begin{abstract}
The region model analysis is an important method for analyzing the interior fire hazard. Based on the mass conservation equation and energy conservation equation of the pre-flashover interior fire hazard development, the formulae required by computer programming are derived. VB is utilized as a tool for developing computation program with the aid of object programming idea to apply the mathematical modelling theories of the release rate of fire heat, plume and heat transfer. The relevant programming procedures and computation flow chart are presented. The program is verified through experimental data from Tianjin Fire Research Institute. As the computation of plumes is oversimplified, the thickness change of the smoke layer and the results obtained in the experiment vary considerably. The main advantage of the proposed computation model is that it is ease to be utilized for a variety of occasions.
\end{abstract}

Keywords: Regional model simulation, fire hazard, plume, security, model.

\section{Introduction}

The development of the fire hazard is a complicated and uncertain process. In order to study the characteristics of the fire hazard effectively, the development process of the fire hazard is divided into several stages for analysis and simulation (Hu et al. 2005). At the early stage of the fire hazard, the study mainly focuses on describing physical and chemical phenomena in the fire hazard development process with mathematical language, namely, mathematical modeling. Then the models which manifest the characteristics of the fire hazard are integrated together to form a complete process model of the fire hazard. Finally, the simulation results are obtained through computer simulation techniques. The region model, playing an important role in the interior fire hazard study, is a kind of deterministic the fire hazard analysis module. It is significant importance to study the computer simulation of the interior fire hazard for the building fire-proof and the fire hazard resistance research (Jain et al. 2008).

The region model of the fire hazard is the most basic model for the quantitative researches on the building fire. Actually, since the last century, the researches on region models have been carried out in many countries (Lee et al. 2010). In the 1950s, Kawagoe et al. (1964) proposed a region model describing the single-floor and the single-room fire hazard, determined the interior heat balance equation and finally obtained the air temperature-time curve for the fire hazard through using the numerical method. His researches promoted the mathematical modeling in the fire hazard process. Subsequently, Magnussen et al. (1976) provided the mass conservation equation as a supplement, laying a foundation for the study on the fire hazard. Thomas et al. (2007) added the heat balance equation of the fuel surface, and established the interior reaction kinetic equation with a finite rate. Bfhm attempted to solve the unstable heat balance

\section{Chen Cao}

Engineering Faculty, University of Wollongong, Australia ccao@uow.edu.au

Northfields Ave, University of Wollongong, NSW2522, Australia +612425334939

\author{
Manuscript Code: 570 \\ Date of Reception/Acceptance: 12/12/2014-01/03/2015
}

Resumen

El análisis del modelo de región es un importante método para analizar el riesgo de incendio interior. Sobre la base de la ecuación de conservación de energía y ecuación de conservación de la energía del desarrollo del peligro de incendio interior por combustión súbita, se derivan las fórmulas requeridas para el software informático. La herramienta VB se utiliza para el desarrollo de programas de computación con la ayuda de programación a objetos para aplicar las teorías de modelización matemática de la velocidad de liberación de calor fuego, penacho de fuego y transferencia de calor. Se presentan los procedimientos de programación pertinentes y diagrama de flujo de cálculo. El programa se verifica a través de datos experimentales del Instituto de Investigación de Incendios de Tianjin. Como se sobre-simplifica el cálculo de los penachos, el cambio de espesor de la capa de humo y los resultados obtenidos en el experimento varían considerablemente. La principal ventaja del modelo de cálculo propuesto es su facilidad para ser utilizado en una variedad de situaciones.
Palabras Claves: Simulación de modelos de región, riesgo de incendio, penachos de fuego, seguridad, modelo.

equation. Later, some scholars also continued to improve the heat balance equation. All their endeavors contribute a lot to the rapid increase in the mathematical equations, but at the same time, they have made the numerical solution become increasingly complicated. With the development of numerical techniques, Emmons (1958) first proposed the region model, which has undergone rapid development. In early 1980s, Emmons applied the mass conservation, energy conservation, momentum conservation and chemical reaction principle in the studies on the building fire hazard through using the method of the mathematical analysis. He created a precedent for the researches on the mechanism of fire hazard process. In addition, he promoted the theoretical research fruits of the fire hazard science to engineering. On the basis of Emmons's studies, foreign researches on the fire hazard science began to focus on the dynamic process at the initial stage of the fire hazard, that is, the fire hazard development before the flashover. The scholars expected that they could grasp the law of fires at the early stage as much as possible through the in-depth researches and that they could extinguish the fire hazard at this stage. With the rapid development of the computer technology and numerical methods, it is not difficult to solve the complicated mathematical problems. As a result, the researches on the dynamic model of the fire hazard have undergone rapid development at this stage.

The scholars from University of Science and Technology of China first proposed the idea of dual nature of fire hazard and the theories of the field-region simulation and field-region-networking simulation for the building fires, which attracted much attention of scholars at home and abroad. In terms of the fire network simulation technology, China University of Mining \& Technology (Beijing) has reached the advanced international level, and they have already applied the one-dimensional network simulation technology to the researches on high-rise building fires. Chen et al. (2007) investigated 
the application of virtual reality technology to building fire simulation and presented the methods for simulating a fire in an interactive virtual environment. Due to the spreading of flames and smoke in the virtual fire scene was based on the simulation results of fire simulation, so the results were similar to that in the real life. In order to analyze and evaluate fire impact on structural safety of equipment, building and other sensitive objects, song et al. (2012) proposed strategies and implementation procedures of probabilistic fire safety analysis with reference to chemical process quantitative risk analysis approach and probabilistic gas explosion study approach. Referring to the data of a room fire test and selecting different opening position and ignition location at three representative conditions to be simulated, Niu et al. (2014) carried out the comparison between simulated results and experimental data and found that the simulation results were high reliability and FLUENT software could accurately predict the conditions of fire smoke flow and temperature distribution for various room situations. On the whole, China's fire science has undergone the rapid development.

At present, the sophisticated mathematical models for smoke movement of building fires falls into three kinds: network model, region model and field model. For the smoke movement in the high-rise building fire, these models have their own advantages and disadvantages (Ji et al. 2011). Only by combining two or more of them together, that can give full play to their respective advantages. Ultimately, a numerical simulation method can be found to solve the smoke movement of building fires in a more appropriate way. So far, although la large number of computer models for building fires can be used, they are different in two aspects: application scope and complexity degree. For example, ASET is only suitable for single-room fire computing; COMPFZ and FIRST are suitable for the computation of interior temperature after flashover (Yang et al. 2005; Ahmed 2013; Chow 1996). Typically, the development process of the interior fire hazard is described through a curve of average temperature of the interior smoke changing over time (Pei et al. 2008). However, in many cases, the temperature of the interior fire hazard is affected by many factors, including the locations and sizes of the fire sources, types, quantity and surface areas of combustible materials, locations and areas of the window and door openings, thermal performance of the building materials and so on. In this paper, based on previous researches, the authors attempt to establish a simple interior fire computation model suitable for various occasions through using the region model method, and verify the rationality of the computation model through experimental data.

\section{Description of the problem}

From the current view of the advances in fire smoke, the experimental method and the computer simulation are still the main research methods and the evaluation of the smoke harm is mainly by the use of the experimental and calculated results together. The basic steps of a fire simulation:

(1) Modeling and meshing: The geometric model is built and the grids of the model are reasonably divided by using the related software according to the building structure, fire scenes and the external environment, etc.

(2) Setting the control equations and boundary conditions: After selecting the control equations, the turbulence model and the radiation model, the relevant boundary conditions, initial conditions, physical parameters, ambient temperature and pressure, etc. must be set.
(3) Simulation: The calculation process can be monitored by the parameters convergence curve of the monitoring points, and the reasonableness of the calculated results can be determined by the intermediate calculations results.

(4) Value processing: The specific values can be processed through post-processing calculations and shown by the cloud map. Then the results can be analyzed.

For the fire source design of a region model of the interior space on the fire hazard, it can be seen as Figure 1. The fire source design can be adopted by two ways in the practical engineering. One method is that the volume heat source is used to simulate the fire. This method can save a lot computing time and it does not consider the combustion reaction. The fire source is assumed to be the source volume heat and smoke. Another method is that the built combustion model is used to simulate the fire. In consideration of the combustion reaction requires very fine grids, and it takes a lot of computing time, therefore, this method is less used in the engineering calculations.

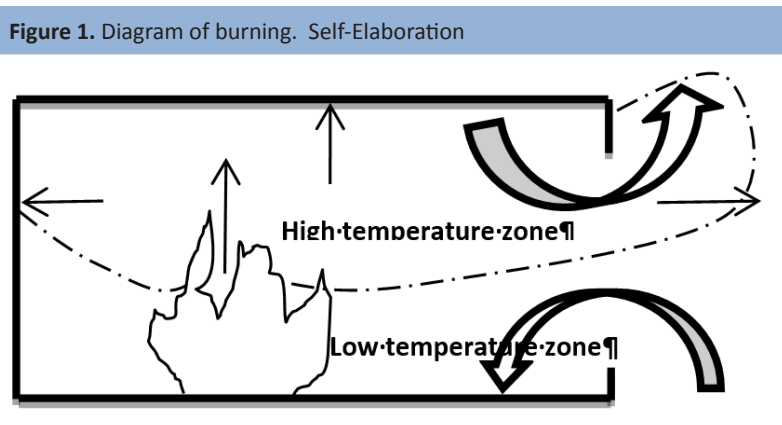

Judging from the contents of a computer simulation of the smoke, we can found that it focused on the physical movement of the flue gas, which is a relatively small during the chemical reaction process in the simulation. Another point is that most of the computer simulations are based on the experimental law and on the empirical formula, and there is few completed theoretical models. Since there is an important effect on the development of a fire and smoke by the limited geometry of the space and ventilation, it is necessary to calculate the fire random and to combine the deterministic calculations and the fire random in the development of computer simulation techniques. And this is also a focus on the development of computer simulation (Huang et al. 2002; Niu et al. 2011; Munoz et al. 2012).

Methodology. Basic assumptions and computation equation of region model.

\section{(a) Basic assumptions}

Region model refers that the interior space on the fire hazard is artificially divided into several different parts, generally, two parts: upper hot smoke layer and lower cold air layer. They are relatively stable before flashover. In order to solve the problem, let's assume that various interior parameters are uniformly distributed and they are all functions of time. According to the burning remnants on the fire scene, it proves that this assumption is relatively reasonable. In order to further simplify the problem, this region model is assumed as follows (Merci et al. 2008): (1) The upper smoke layer and the lower cold air layer inside the room are uniform respectively, and the temperature, pressure and the concentration of components 
of combustion products are uniform in physical parameters. (2) There is a clear interface between the upper layer and the lower layer; and this interface has no heat transfer or mass transfer or continuity. (3) Combustion products, effective heat and the entrained air all go into the upper hot air layer through the plumes and once they go into the upper layer, they are immediately mixed with the upper air thoroughly. (4) The lower cold air layer is treated as heat transparency and the direct heat radiation of the flame and plumes against the upper hot air layer and lower layer is ignored. (5) The air at the upper and lower layers and around them is regarded as ideal air. The pressure change indoors and outdoors is ignored, which is considered as isobaric process.

For the fire hazard with the flashover, the interior space is viewed as a uniform high-temperature heat layer, ignoring the plumes and air entrainment model. In this paper, the region model is only for the case in which the flashover occurs.

\section{(b) Computation equation}

The structure in the region model which is damaged in the fire hazard is subject to the temperature in the fire space and the length of fire time. The structural damage is mainly caused by the baking at high temperature. Based on the assumption that two sub-zones in the model are uniform, the upper high temperature smoke layer is mainly investigated, which is shown in Figure 1. According to the mass conservation law and energy conservation law, it is not difficult to establish two equations for high-temperature sub-zones (Zhan et al. 2005):

1) Mass conservation equation:

$\dot{m}_{G}=\dot{m}_{P}-\dot{m}_{L}$

$m_{G}=\rho_{G}\left(H_{f}-Y\right) A_{f}$

In these equations, $\dot{m}_{G}$ is the mass growth of hot air layer; $\dot{m}_{P}$ is the mass flow into the upper layer through the plumes, including the mass flow of combustion products (CO, CO2, smoke particles, etc.) and plume-entrained air; $\dot{m}_{L}$ is the mass flow out of the upper opening; $m_{G}$ is the mass of hot air layer; $\rho_{G}$ is the density of hot air layer; $H_{f}$ is the height of the room; $Y$ is the height of hot air layer; $A_{f}$ is the floor area of the room.

2) Energy conservation equation:

$\dot{Q}_{G}=\dot{Q}_{E}+\dot{Q}_{P A}-\dot{Q}_{L}-\dot{Q}_{R}-\dot{Q}_{C W}-\dot{Q}_{R W}$

In the equation, $\dot{Q}_{G}$ is the energy growth rate of hot air layer; $\dot{Q}_{E}$ is the effective heat produced by combustion (Effective heat release rate, that is, the heat losses caused by flame radiation is deducted from the heat released by burning); $\dot{Q}_{P A}$ is the energy of mass flow into the hot air layer (plume and entrained air); $\dot{Q}_{L}$ is the energy flow of hot air layer flowing outside through the opening; $\dot{Q}_{R}$ is the energy flow of hot air layer radiated to the outside through the opening; $\dot{Q}_{C W}$ is the convection exchange between the hot air layer and the walls and ceiling; $\dot{Q}_{R W}$ is the radiation heat transfer between the hot air layer and the walls and ceiling. In the high temperature partition, let's assume that the air is the ideal isobaric uniform air. Considering the heat exchange between the low temperature zone and the high temperature zone and energy losses in the high temperature zone caused by heat radiation and conduction outwards, the following basic equations can be deduced:

$\dot{T}_{G}=\frac{\left(U-\dot{Q}_{P}\right) T_{G}}{C_{P} T_{A} \rho_{A} A_{f} Z}$

$\dot{Z}=\frac{U-\dot{Q}_{L}}{C_{P} T_{A} \rho_{A} A_{f}}$

$U=\dot{Q}_{E}+\dot{Q}_{P A}-\dot{Q}_{R}-\dot{Q}_{C W}-\dot{Q}_{R W}$

In these equations, $T_{A}$ and $\rho_{A}$ refer to the temperature and density of air at the room temperature; $\mathrm{Z}$ is the thickness of hot air layer; $C_{P}$ is specific heat capacity of air; $\dot{Q}_{P}$ is the energy of the high-temperature plumes.

The above ordinary differential equations are the deduced simulation equations for temperature and thickness of the upper hot air layer indoors (Rho et al. 1999).

\section{(c) Computation program development}

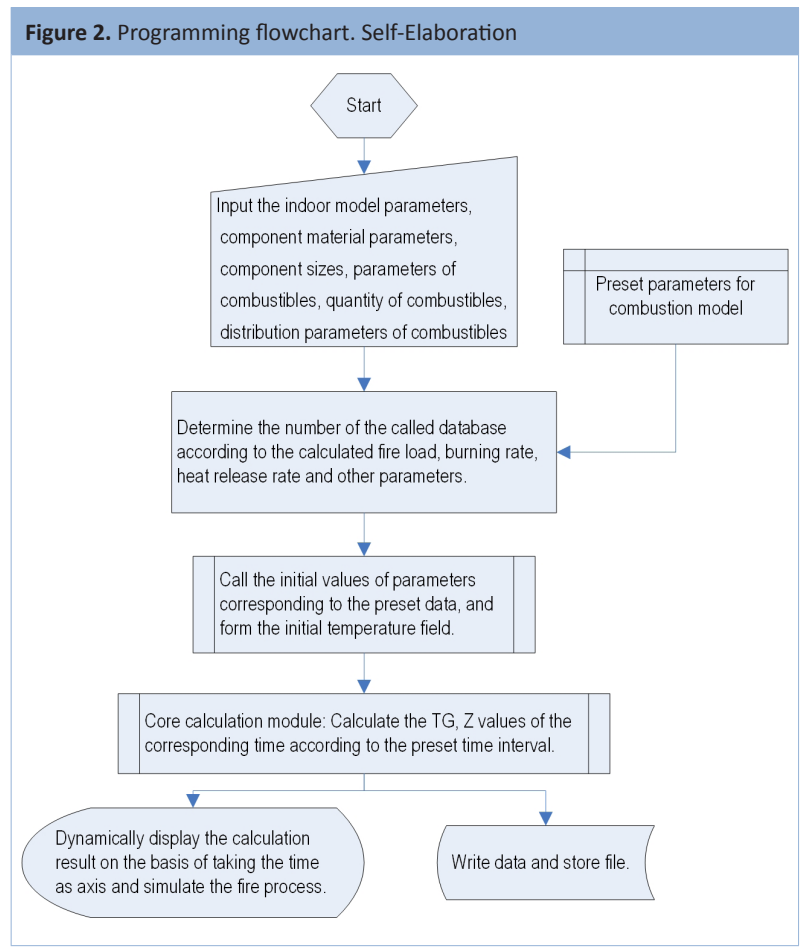

In the region model, the interior fire consists of four processes: fire source, plume, open flow and heat transfer. In the equation, the solution of unknown quantity depends on the establishment of models for processes of fire. The above theories are taken as the basis of programming; VB is utilized for development and design as a programming language; 'Access' is utilized for the creation of database. The idea of modular design is used for programming; specifically, the relevant functional modules are separated for future upgrades and revision. The main idea of programming is shown in Figure 2.

Calculation program components: the initialization procedure 
preset parameters, automatic classification of the subroutine flame and smoke layer unit, the solution of ordinary differential equations subroutine, data storage subroutine and so on. The main outputs: hot smoke layer temperature and thickness, graphic animation.

\section{Results}

Tianjin Fire Research Institute has carried out several experiments on fires in the hotel rooms, and conducted the tests on the temperature and smoke layer in the room on fire hazard (Chen et al. 2008). These experiments are taken as an example of computation verification:

In the experiments, the room on fire is wide $3.33 \mathrm{~m}$, long $3.82 \mathrm{~m}$ and high $3.6 \mathrm{~m}$. And an opening of $0.88 \mathrm{~m} \times 2.15 \mathrm{~m}$ is cut. The combustibles refer to those commonly used modern furniture, and their arrangement is shown in Figure 3.

Figure 3: (a) Simmons bed assembly, including synthetic fabrics of $1 \mathrm{~kg}$, PU foam of $0.3 \mathrm{~kg}$, palm of $3 \mathrm{~kg}$, linen of $3 \mathrm{~kg}$, cotton of $1.5 \mathrm{~kg}$, Raschel blanket of $3.74 \mathrm{~kg}$, quilt of $2.96 \mathrm{~kg}$, cotton bed-sheet of $0.34 \mathrm{~kg}$, and buckwheat husk pillow of $3.34 \mathrm{~kg}$; (b) Wooden bedside tables; (c) Wooden writing desk; (d) Wooden soft chair.

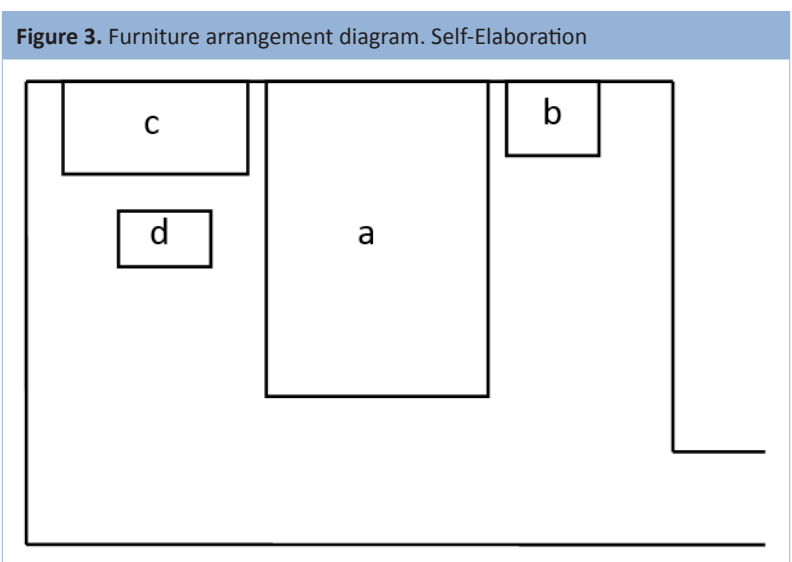

In the ignition, the absorbent cotton of $3 \mathrm{~g}$ soaked in $25 \mathrm{ml}$ gasoline is used as the fire source. In addition, the phenomenon of flashover never occurs in the experiments. Based on these data, the computation is conducted using the program. The comparison results between the calculated height of the smoke layer and the result measured in the experiment are shown in Figure 4.

It can be seen from the analysis and comparison of two diagrams that, under the premise of ignoring accidental factors, this programming simulation approaches the actual observation data, showing the simulation computation theories in this program is correct. However, as there are the following deficiencies, there is necessity to deepen the study on the model.

(1) In the temperature simulation of the smoke layer, the program fails in effectively simulating the attenuation stage of temperatures, and the result is closer to the shape of standard temperature curve (Chen et al. 2008). Because the calculation value is the average temperature of the smoke layer, with the development of time, distance of flue gas temperature can better reflect the average temperature of the hot air layer.

(2) In the thickness simulation of smoke layer, the computation of plumes is oversimplified and the thickness change of the smoke layer and the results obtained in the experiment vary considerably. The theoretical background and experimental conditions with the plume model is different, it lead to a big difference of plume volume estimates between the absorption rates, thereby affecting the regional simulation accuracy of the predicted results.

Under different circumstances, the emphasis is not the same. For lightweight steel, the influence of maximum temperature is the most important. For the concrete, the entire duration of heating is the most critical. Therefore, in order to facilitate practical use, there is necessity for further research.

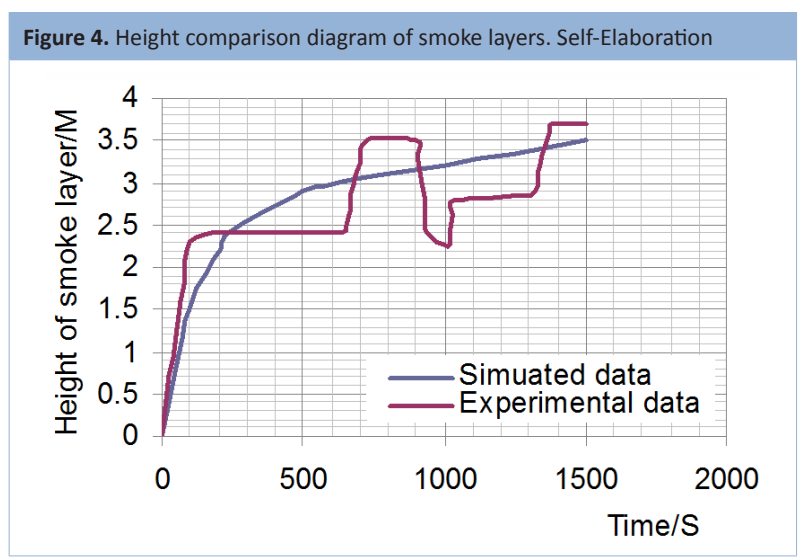

Figure 5. Temperature comparison diagram of smoke layers. Self-Elaboration

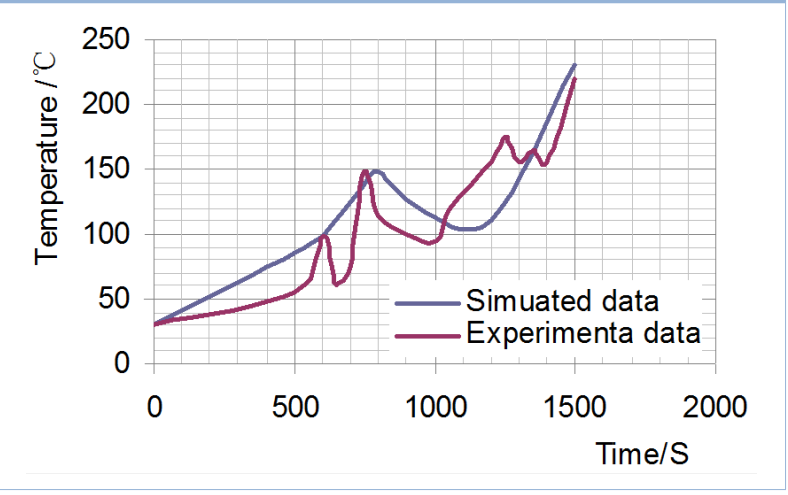

Conclusion

The computation model proposed in the paper has its advantages and disadvantages. One of the main advantages is that it's ease to be utilized for a variety of occasions. But it has one main disadvantage, that is, the fuel pyrolysis rate has not yet coupled with the heat transfer process, so the setting is required for practice.

The simulation of the fire hazard is based on the existing fire models for the program design and simulation computation. In the simulation of the real fire hazard, there are two critical factors: the rationality of the program design and the correctness of the simulation computation.

As the environmental factors of the fire hazard are complicated and the fire hazard has the great occasionality, it is difficult to use an accurate test device to monitor the fire hazard process. But in the engineering practice, some similar disaster informations are required for the engineering service, so the simulation computation has become a cost-effective means. 
Due to the computation model being oversimplified, the thickness of the smoke layer varies considerably compared with the results obtained in the experiment. Therefore, in order to facilitate the practical use, there is necessity to deepen the research in the future.

\section{References}

Ahmed, M. (2013). Salem Parametric analysis of a cabin fire using a zone fire model. Alexandria Engineering Journal, 52(4), 627-636.

Chen, A. P., Liu, B., \& Yang, S. S. (2010). Theoretical analysis and experimental study on backdraft. Journal of Thermal Science and Technology, 9(4), 348-355.

Chen, C., Ren A. Z., \& Zhang X. (2007). A building fire simulation system based on virtual reality. Journal of Natural Disasters, 16(1), 55-60.

Chen, K. C. \& Yao, B. (2008). The applicability of the model of the smoke plume simulation of indoor fire area, Combustion Science and Technology, 14(4), 296-299.

Chow, W. K. (1996). Simulation of tunnel fires using a zone model. Tunnelling and Underground Space Technology, 11(2), 221-236.

Emmons, H.W. (1958). Fundamentals of Gas Dynamics. Princeton (New Jersey): Princeton University Press.

Hu, K. X., \& Hu, K. H. (2005). On a regional model of the limitations of simulation Arcade Fire large. Sichuan Building Science Research, 31(5), 12-14.

Huang R., Yang L. Z., Fang W. F., Fan W. C. (2002). Progress in study of Hazard Analysis of Fire Smoke. Engineering Science, $4(7)$ 80-85.

Jain, S., Kumar, S., \& Sharma, T. P. (2008). Numerical simulation of fire in a tunnel-Comparative study of CFAST and CFX predictions. Tunnelling and Underground Space Technology, 23(2), 160-170.

Ji, J. J., Hao, Y. H., Wang, Y. E. \& Li, J. G. (2011). Heat radiation calculation of two regional fire in the Monte Carlo method. Journal of China University of Mining and Technology, 40(2), 180- 184

Kawagoe, K. \& Sekine, T. (1964). Estimation of Fire Time-Temperature Curve in Rooms. BRI Occasional Report No. 17, Building Research Institute, Ministry of Construction, Tokyo.

Lee, Y. H., Kim, J. H., \& Yang, J. E. (2010). Application of the CFAST zone model to the Fire PSA. Nuclear Engineering and Design, 240(10), 3571-3576.
Magnussen, B. F., \& Hjertager, B. H. (1976). On Mathematical Modelling of Turbulent Combustion with Special Emphasis on Soot Formation and Combustion. 16th International Combustion Symposium, Combustion Institute, Pittsburgh, PA.

Merci, B. \& Maele, K. V. (2008). Numerical simulations of full-scale enclosure fires in a small compartment with natural roof ventilation. Fire Safety Journal, 43(7), 495-511.

Munoz, C., \& Bobadilla, A. (2012). Simulation and evaluation of thermal bridges typical constructive solutions approved by the thermal norm for vertical elements in structure of wood and metalists in zone 4. simulations with therm and usai and evaluation with method of thermal camera, Revista de La Construccion, 11(2), 92-111.

Niu G. L., Tang Y. G., \& Xia C. T. (2011). Theoretical study and simulation on smoke layer height in enclosure fires. Science Technology and Engineering, 11(22), 5355-5360.

Niu K., Zhi H. Q., \& Bai D. T. (2014). Study of Reliability for FLUENT Based on single Room Fire Test, Journal of System Simulation, 26(11), 2810-2814.

Pei, B., Yu, M. G. \& Liu, H. (2008). Numerical simulation method and evaluation for building fires. Journal of Henan Polytechnic University, 27(1), 12-16.

Rho, J. S. \& Ryou, H. S. (1999). A numerical study of atrium fires using deterministic models. Fire Safety Journal, 33(3), 213-229.

Song X. S., Chen C., \& Liu Y. X. (2012). Study on Probabilistic Fire Safety Analysis Procedures. China Safety Science Journal, 22(1), 39-45.

Thomas, C., \& Foken, T. (2007). Flux contribution of coherent structures and its implications for the exchange of energy and matter in a tall spruce canopy. Boundary-Layer Meteorology, 123(2), 317-337.

Yang, L. Z., Guo, Z. F. \& Ji, J. J. (2005). In the fire development mode based on the regional simulation. Chinese Science Bulletin, $12,1272-1277$.

Zhan, G. J. \& Mao, Y. W. (2005). Analysis of fire temperature field in buildings. Journal of Xingtai Polytechnic College, 22(1), 67-69.

Zhang, X. T., Wang, S. J, Wang, J. L. \& Giacomo, R. (2014). A Simplified Model to Predict Smoke Movement in Vertical Shafts During a High-Rise Structural Fire. Journal of Engineering Science and Technology Review, 7(2), 22-28. 
bianjie(Source.Index).x=Source.Left

bianjie(Source.Index).y=Source.Top

If Source.Index $=1$ Then

Line_(1).x1=bianjie(1).x + jiadian(0).Width / 2

Line_(1).y1=bianjie(1).y - jiadian(0).Width / 2

Line_(1).x2=bianjie(2). $x+$ jiadian(0).Width $/ 2$

Line_(1).y2=bianjie(2).y - jiadian(0).Width $/ 2$

Else If Source.Index=bianjie1 Then

Line_(Source.Index-1).x1=bianjie(Source.Index-1).x+jiadian(0). Width/2

Line_(Source.Index-1).y1=bianjie(Source.Index-1).y-jiadian(0). Width/2

Line_(Source.Index-1).x2=bianjie(Source.Index).x+jiadian(0). Width/2

Line_(Source.Index-1).y2=bianjie(Source.Index).y-jiadian(0). Width/2

Else

Line_(Source.Index-1).x1=bianjie(Source.Index-1).x+jiadian(0). Width/2

Line_(Source.Index-1).y1=bianjie(Source.Index-1).y-jiadian(0). Width/2

Line_(Source.Index-1).x2=bianjie(Source.Index).x+jiadian(0). Width $/ 2$

Line_(Source.Index-1).y2=bianjie(Source.Index).y-jiadian(0). Width $/ 2$

Line_(Source.Index).x1=bianjie(Source.Index).x + jiadian(0). Width/2

Line_(Source.Index).y1=bianjie(Source.Index).y - jiadian(0). Width / 2

Line_(Source.Index).x2=bianjie(Source.Index+1).x+jiadian(0). Width/2

Line_(Source.Index).y2=bianjie(Source.Index+1).y-jiadian(0). Width/2

End If 